\title{
Hybrid Power Systems for Buildings and Factories
}

\author{
Chung-Jen Tseng ${ }^{1,2, *}$, Cheng-I Chen ${ }^{2,3}$, Cheng-You Yao ${ }^{1}$ and Kan-Rong Lee $e^{1,4}$ \\ ${ }^{1}$ Department of Mechanical Engineering, National Central University, Taoyuan City, Taiwan. \\ ${ }^{2}$ Center for Energy Research, National Central University, Taoyuan City, Taiwan. \\ ${ }^{3}$ Department of Electrical Engineering, National Central University, Taoyuan City, Taiwan. \\ ${ }^{4}$ Institute of Materials Science and Engineering, National Central University, Taoyuan City, Taiwan.
}

\begin{abstract}
Integrated hybrid power systems have become more and more important in recent years. The functioning of medium-temperature proton-conducting solid oxide fuel cell (pSOFC) hybrid system is proposed in this work. The combined system consists of a pSOFC stack, steam methane reformer, compressors, burners, heat exchangers and methanol synthesizing reactor. The excess waste heat of the burner is recovered using heat exchangers. Also, the unutilized hydrogen from SOFC is used for carbon reduction by methanol production. The functioning of configured system is explored by using Matlab/Simulink/Thermolib software. In pSOFC operation, stoichiometric ratio (Sto) of air is maintained 3 and Sto of hydrogen is varied between 1.4 to1.7. Results show that the benefit of carbon reduction depends on methanol production. By using water separator, the methanol production efficiency increases dramatically. In addition, hydrogen transfer membrane is used to increase stack efficiency and control the temperature of stack chamber and reformer. This further improves benefit of carbon reduction. The proposed hybrid system in this work can be used to power huge residential buildings and some factories.
\end{abstract}

\section{Introduction}

Fuel cell is an efficient device to convert molecular energy straight away into electricity. High-temperature solid oxide fuel cell (HT-SOFC) functions in the temperature range of $800-1000{ }^{\circ} \mathrm{C}$. HT-SOFC operation temperature allows its use in a hybrid system with a gas turbine (GT) or micro gas turbine (MGT), or a combined heat and power system. Integration of residual biogas generation system as a source of hydrogen generation by steam methane reforming (SMR) could effectively reduce the cost of hydrogen fuel generation for SOFC. The asgenerated hydrogen can be fed to HT-SOFC for industrial power generation as mentioned by Gandiglio et al [1]. The unutilized hydrogen from SOFC can be effectively used for methanol production. Methanol is widely used as raw material for producing formaldehyde, synthetic resins, pharmaceuticals, and pesticides in organic factories. So, the SOFC hybrid systems can be used as a source of power and raw material generation in organic chemical factories. The carbon imprint in power generation and raw material production for the mentioned organic factories can be stockpiled. Such hybrid systems also avoid the mitigation of currency outflow in a factory. But in HT-SOFC, high heat resistant alloys and ceramics are only feasible for balance-of-plant (BOP) components in the HT-SOFC operation range. Therefore, it is significant to reduce the operating temperature to the range of $550-650{ }^{\circ} \mathrm{C}$ (intermediate-temperature, IT). Reducing operation temperature favors the usage of low-cost materials for
BOP, quick start and off, lowered corrosion rate of metallic components with enhanced endurance.

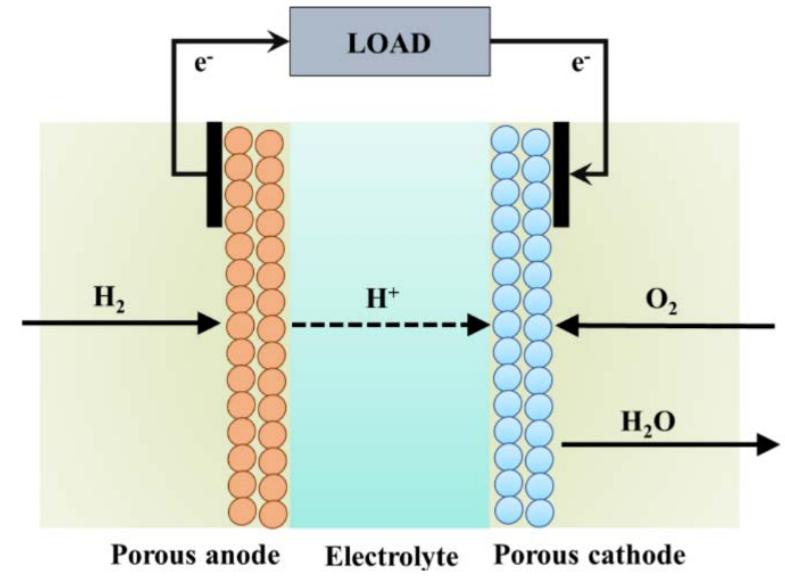

Fig. 1. Schematic of a proton-conducting SOFC.

Proton-conducting SOFC (pSOFC) favors reducing the operation temperature [2]. The mechanism of pSOFC is shown in Fig. 1. The smaller size of proton aids better conductivity compared to an oxide ion in the electrolyte with lower activation energy. Thus, the high fuel utilization at anode with higher hydrogen partial pressure caused higher efficiency of the pSOFC. Based on the comparative thermodynamic analysis of $\mathrm{pSOFC}$ and oxygen-ion electrolyte SOFC (oSOFC) investigated by Demin et al. [3, 4], methane and hydrogen fed pSOFC show high chemical to electrical energy conversion compared to oSOFC. Ni et al. $[5,6]$ notice that the

\footnotetext{
* Corresponding author: cjtseng@g.ncu.edu.tw
} 
concentration losses in pSOFC and oSOFC are different. pSOFC has low anode concentration and high cathode concentration losses. Water vapor generation at the cathode influences the cathode concentration losses in pSOFC. Moreover, the difference in the performance of oSOFC and pSOFC is observed with larger fuel utilization in ammonia fed SOFCs. The lower steam and higher hydrogen partial pressures of pSOFC compared to oSOFC favors better efficacy of pSOFC than oSOFC. Patcharavorachot et al. [7] has developed and validate a design for $\mathrm{j}-\mathrm{V}$ curve of pSOFC based on $\mathrm{SrCeO}_{3}$ electrolyte. They also investigated the cell performance with variation in thickness of electrolyte and electrodes in the cell. Results suggest that, the major voltage loss is attributed to the ohmic losses and low proton conductivity of the electrolyte. The anode-supported pSOFCs exhibits superior performance.

The high temperature waste flue gas from SOFC can be used for excess power generation by Rankine/Brayton cycles for heating and cooling purpose (cogeneration/ trigeneration) [8]. In general, a contradictory tendency is observed in the electric and cogeneration efficiency in a co-generation system. However, electric efficiency should be prioritized in the designing and selection of a system, as electric energy is of superior quality compared with thermal energy [9]. Yi et al. simulate $25 \mathrm{~kW}$ SOFC integrated reformer system with a CHP and GT/MGT. In SOFC-GT-CHP combined system. A significant decrease in the exhaust heat loss of coal syngas is expected for higher system efficiency. Whereas in replacement of GT with MGT in combined system, electrical efficiency decreases with increase in turbine inlet temperature but the CHP efficiency enhances [10]. In accordance with required energy outcome of the system, the operating conditions of all the components in the hybrid system should be modulated to achieve optimum operating condition [11]. The high temperature operation of SOFC paves way for designing different combinations of systems. Braun et al. discussed the feasibility of SOFC micro combined heat and power generators for daily usage in house hold applications by proper recycling of exhaust gas heat for heating water to $60{ }^{\circ} \mathrm{C}$ along with preheating of input fuel and air [12]. The $\mathrm{CO}_{2}$ capture and storage units can be attached to the SOFC integrated gasification combined cycles or fuel cells to reduce carbon emission [13-16].

Earlier studies on pSOFC are focused on developing materials or thermodynamic performance of fuel cell system. oSOFC is considered for developing hybrid systems. But, pSOFCs possess high efficiencies compared to oSOFCs. So, there is substantial scope to setup IT-pSOFC hybrid systems for low temperature operation advantages $[3,4]$. The low temperature $\left(60^{\circ} \mathrm{C}\right)$ hot water generation from waste heat can be utilized in residential buildings/complex. The power and cost for hot water generation in huge buildings or complex can be decreased. Thus, IT-pSOFC can be used as power source for buildings. Also, such hybrid systems promise continuous and distributed power supply by avoiding power fluctuations in peak demand.
In this study analysis of IT-pSOFC hybrid systems will be discussed in detail. Activation, concentration and ohmic losses in pSOFC system will be investigated by an electrochemical model. The activation and ohmic losses are evaluated by Butler-Volmer equation and ionic conductivity of electrolyte. Whereas, the concentration losses can be determined by the Fick's diffusion through porous electrode. Experimental results from literature are used for validation of simulation data. The proposed study includes a $20 \mathrm{~kW}$ pSOFC, MGT, methanol production, HTM and heat exchangers to heat water upto $60{ }^{\circ} \mathrm{C}$ by waste heat recovery. The proposed hybrid IT-SOFC designs of this study can be used for huge residential buildings/complex and organic chemical factories.

\section{Theoretical model}

\subsection{Proton-conducting solid oxide fuel cell (pSOFC)}

A pSOFC consists of two electrodes separated by an electrolyte. The electrochemical reactions in pSOFC are:

$$
\begin{gathered}
\text { Anode: } 2 \mathrm{H}_{2} \rightarrow 4 \mathrm{H}^{+}+4 e^{-} \\
\text {Cathode: } \mathrm{O}_{2}+4 \mathrm{H}^{+}+4 e^{-} \rightarrow 2 \mathrm{H}_{2} \mathrm{O} \\
\text { Overall: } 2 \mathrm{H}_{2}+\mathrm{O}_{2} \rightarrow 2 \mathrm{H}_{2} \mathrm{O}
\end{gathered}
$$

Standard reversible cell potential is considered to evaluate ideal open-circuit voltage:

$$
V_{r}^{0}=-\frac{\Delta g^{0}}{n F}
$$

where $\Delta g^{0}, \mathrm{n}$ and $\mathrm{F}$ are the Gibbs free energy change at the standard pressure and temperature, the number of moles of electrons transferred and Faraday constant, respectively.

Effects of temperature and pressure on reversible cell potential can be described as:

$$
V_{r}=V_{r}^{0}-\frac{\Delta s}{n F}\left(T-T_{0}\right)-\frac{\Delta N R T}{n F} \ln \left(\frac{P}{P_{0}}\right)
$$

where $\Delta s$ is the change in entropy. $\Delta N$ is the change in the number of mole of gaseous species in the reaction per mole of fuel.

The operation voltage $\left(V_{\text {cell }}\right)$ is always less than the reversible potential due to irreversible losses and can be expressed as:

$$
V_{\text {cell }}=V_{r}-V_{\text {act }}-V_{\text {ohm }}-V_{\text {conc }}
$$

where $V_{\text {act }}, V_{\text {ohm }}, V_{\text {conc }}$, represent the activation, ohmic, and concentration polarizations, respectively.

The sluggish charge transfer reaction across the interface of electrode-electrolyte leads to activation polarization. It is directly related to the rate of electrochemical reaction, which can be determined from the Butler-Volmer Equation:

$$
j=j_{0}\left[\exp \left(\frac{\alpha n F V_{a c t}}{R T}\right)-\exp \left(-\frac{\alpha n F V_{a c t}}{R T}\right)\right]
$$


where $j_{0}$ is the exchange current density, $\alpha$ the transfer coefficient $(=0.5)$.

Ohmic polarization arises due to electrical resistance in the cell. Ionic losses within electrolyte leads to ohmic losses, which obeys Ohm's law:

$$
V_{\text {ohm }}=j \frac{\delta_{\text {electrolyte }}}{\sigma_{\text {electrolyte }}}
$$

where $\delta_{\text {electrolyte }}$ and $\sigma_{\text {electrolyte }}$ are the thickness and ionic conductivity, respectively.

The instantaneous consumption of reactants at electrodes for electrical current output in electrochemical reaction leads to concentration polarization. Also, the reactant availability at the site of reaction due to the limitations in mass transfer influences losses in outcome. $V_{\text {conc }}$ is estimated with reference to the concentration of reactant and products at the interface of electrolyteelectrode. In pSOFC $V_{\text {conc }}$ can be expressed as:

$$
\begin{gathered}
V_{\text {conc, anode }}=\frac{R T}{2 F} \ln \left(\frac{p_{\mathrm{H}_{2}}}{p_{\mathrm{H}_{2}}^{*}}\right) \\
V_{\text {conc,cathode }}=\frac{R T}{2 F} \ln \left[\left(\frac{p_{\mathrm{O}_{2}}}{p_{\mathrm{O}_{2}}^{*}}\right)^{0.5}\left(\frac{p_{\mathrm{H}_{2} \mathrm{O}}^{*}}{p_{\mathrm{H}_{2} \mathrm{O}} \mathrm{O}}\right)\right]
\end{gathered}
$$

where $\mathrm{p}_{\mathrm{H}_{2}}^{*} p_{\mathrm{O}_{2}}^{*}$, and $p_{\mathrm{H}_{2} \mathrm{O}}^{*}$ represent the partial pressure of hydrogen at the anode-electrolyte interface and the partial pressures of oxygen and water vapor at the cathodeelectrolyte interface, respectively. They can be determined as:

$$
\begin{gathered}
p_{H_{2}}^{*}=p_{H_{2}(a)}-\frac{j \delta^{a} R T}{2 F p^{a} D_{a, e f f}} \\
p_{O_{2}}^{*}=p_{O_{2}(c)}-\frac{j \delta^{c} R T}{2 F p^{c} D_{c, e f f}} \\
p_{H_{2} O}^{*}=p_{H_{2} O(c)}+\frac{j \delta^{c} R T}{4 F p^{c} D_{c, e f f}}
\end{gathered}
$$

where $\delta^{a}$ and $\delta^{c}$ are anode and cathode thickness respectively. $p^{a}$ and $p^{c}$ represent the pressure of anode and cathode, respectively. $D_{a, \text { eff }}$ and $D_{c, \text { eff }}$ are the effective mass diffusion coefficients at anode and cathode.

\section{$2.1 \mathrm{j}-\mathrm{V}$ curve validation}

The pSOFC experimental data of Iwahara is used for validation of $\mathrm{j}-\mathrm{V}$ curve [17]. The thickness of electrodes and electrolyte are $50 \mu \mathrm{m}$ and $500 \mu \mathrm{m}$ respectively. The proton conductivity is acquired from Potter and Baker [18]. Fig. 2 depicts good estimation of the $\mathrm{j}-\mathrm{V}$ characteristics of pSOFC operated under normal atmospheric conditions at $800^{\circ} \mathrm{C}, 900{ }^{\circ} \mathrm{C}$, and $1000^{\circ} \mathrm{C}$.

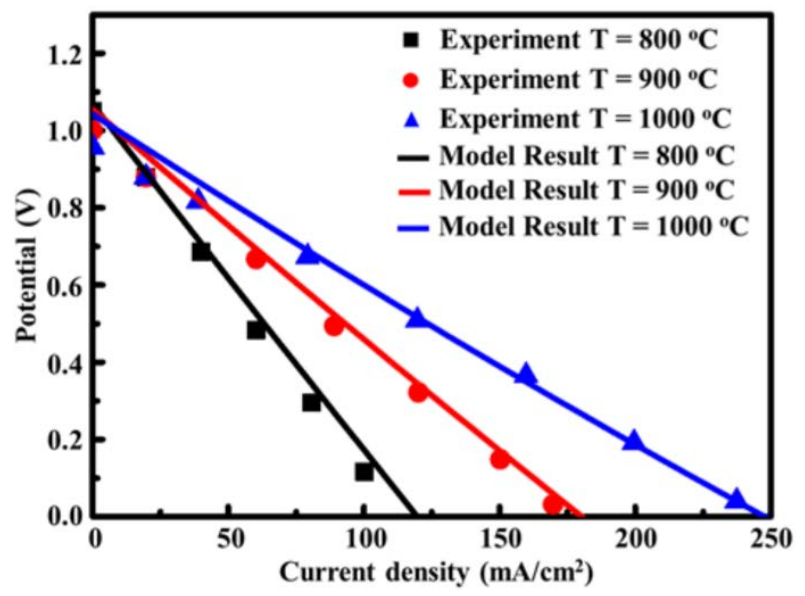

Fig. 2. Comparison between theoretical modeling results and experimental data.
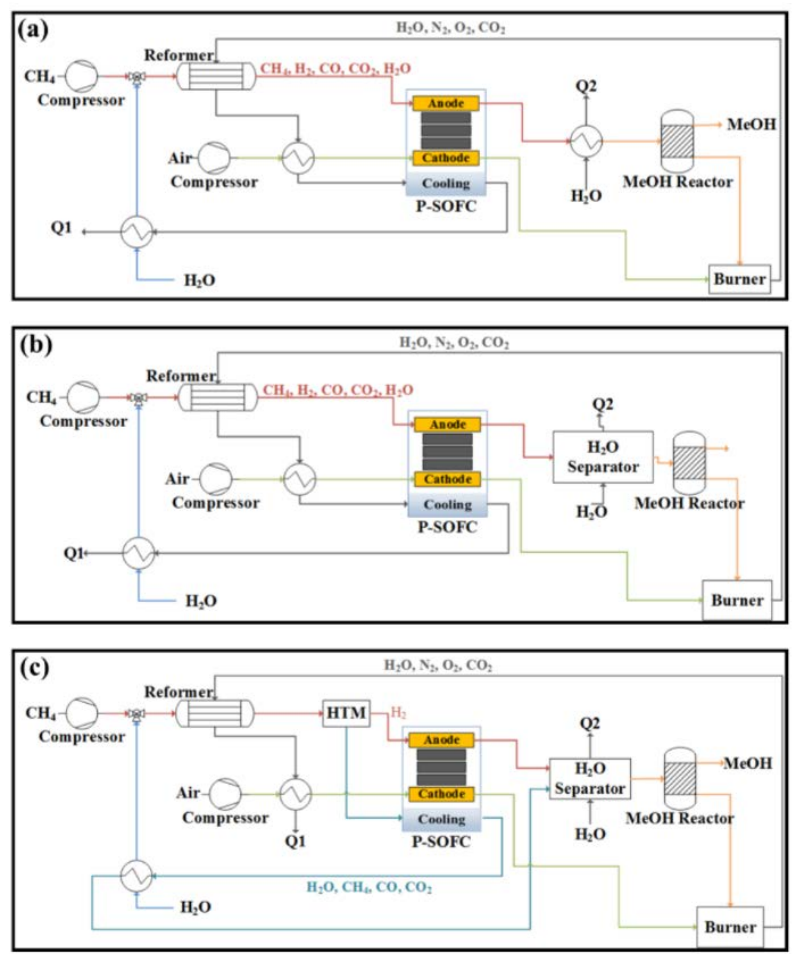

Fig. 3. The IT-pSOFC hybrid system model on (a) initial design (system A), (b) with water separator (system B), and (c) with HTM (system C).

\subsection{System simulation model}

The IT-pSOFC hybrid system efficacy is simulated by using Matlab/Simulink/Thermolib. Thermolib is a simulation toolbox to design and evaluate thermodynamic systems using Matlab/Simulink software. Fig. 3 shows the schematic of the hybrid system configurations (system A, $\mathrm{B}$ and $\mathrm{C}$ ) designed for this study. In this systems, the reactants are compressed to $2 \mathrm{~atm}$ and preheated prior supply to pSOFC stack. The unreacted fuel and air from exhaust of pSOFC stack flows into an afterburner followed by a methanol synthesis reactor for reduction of excess gas. Thereafter, the gas flows around pSOFC to control the stack temperature between $550-650{ }^{\circ} \mathrm{C}$. 
Further, water is heated using hot gas for the heat recovery and enhancement of efficiency of the system. The system parameters of this study are shown in Table 1. The following conditions are assumed to simplify the analysis of system:

1. Steady state system

2. Gases are ideal gases

3. Uniform stack temperature

The modeling of each component is described in the further sections.

Table 1. Operating and system parameters for $20 \mathrm{~kW}$ ITpSOFC hybrid system.

\begin{tabular}{|c|c|}
\hline System parameter & value \\
\hline $\begin{array}{l}\text { Fuel stoichiometric ratio } \\
\text { (Stofuel) }\end{array}$ & $1.4-1.7$ \\
\hline $\begin{array}{c}\text { Air stoichiometric ratio } \\
\text { (Sto air) }\end{array}$ & 3 \\
\hline Operating pressure (atm) & 2 \\
\hline Number of fuel cells & 100 \\
\hline Fuel cell active area $\left(\mathrm{m}^{2} /\right.$ cell $)$ & 0.01 \\
\hline Cell voltage (V/cell) & $0.68-0.72$ \\
\hline pSOFC fuel utilization (\%) & 90 \\
\hline $\begin{array}{c}\text { Compressor isentropic } \\
\text { efficiency }(\%)\end{array}$ & 70 \\
\hline Heat recover efficiency $(\%)$ & 90 \\
\hline Inverter efficiency (\%) & 92 \\
\hline
\end{tabular}

\subsection{Compressor}

The compressor delivers the required outlet pressure with low-pressure inlet flow. It estimates the thermodynamic state of outlet flow along with the necessary mechanical power consumption of a compressor at a given isentropic efficiency. The enthalpy difference in isentropic change of states to actual enthalpy difference is isentropic efficiency.

$$
\eta_{\text {isentropic }}=\frac{\Delta \dot{\mathrm{h}}_{\text {isentropic }}}{\Delta \dot{\mathrm{h}}}
$$

\subsection{Methanol synthesis reactor}

Methanol is one of the most common organic chemicals. Its main uses include the production of formaldehyde, synthetic resins, pharmaceuticals, and pesticides. In this study, residual hydrogen from a fuel cell reaction is reformed with residual methane, producing carbon monoxide and carbon dioxide. The methanol synthesis reactor uses carbon oxide, carbon dioxide, and hydrogen to produce methanol. This reaction improves system efficiency and reduces carbon:

$$
\begin{gathered}
\mathrm{CO}_{2}+3 \mathrm{H}_{2} \leftrightarrow \mathrm{CH}_{3} \mathrm{OH}+\mathrm{H}_{2} \mathrm{O} \\
\Delta \hat{h}_{r x n}^{0}=-49.5 \mathrm{~kJ} / \mathrm{mol} \\
\mathrm{CO}+2 \mathrm{H}_{2} \leftrightarrow \mathrm{CH}_{3} \mathrm{OH} \\
\Delta \hat{h}_{r x n}^{0}=-90.5 \mathrm{~kJ} / \mathrm{mol}
\end{gathered}
$$

\subsection{Afterburner}

An afterburner combusts the fuel that remains from the pSOFC. The enthalpy of combustion for hydrogen is based on the following reaction:

$$
\mathrm{H}_{2}+\frac{1}{2} \mathrm{O}_{2} \rightarrow \mathrm{H}_{2} \mathrm{O} \quad \Delta h=-241.2 \mathrm{~kJ} / \mathrm{mol}
$$

\subsection{Hydrogen transfer membrane (HTM)}

The hydrogen transfer membrane (HTM) uses proton-conducting electrolyte and transfers hydrogen ions to the other side of the membrane. When the HTM separates the hydrogen, the main driving force is the concentration difference between the two sides of the membrane. This element is not assumed to be represented by ideal components of energy; its gas pressure loss is ignored.

\subsection{Water separator}

The water separator condenses water vapor from the gas collected; when the tank is full of water, a solenoid switch drains the tank. This element is not assumed to be represented by ideal components of energy; its gas pressure drop and the power required for the solenoid valve switch are ignored.

\subsection{Efficiency definitions}

$$
\begin{aligned}
\eta_{p S O F C} & =\frac{P_{D C, p S O F C}}{\dot{n} \times L H V} \\
\eta_{s y s} & =\frac{P_{A C, N e t}}{\dot{n} \times L H V} \\
\eta_{\mathrm{MeOH}} & =\frac{n_{\mathrm{MeOH}}+L H V_{\mathrm{MeOH}}}{\dot{n} \times L H V}
\end{aligned}
$$

where $\dot{n}$ denotes the input molar flow rate of fuel in a system; $P_{D C, p S O F C}$ denotes the output power of the stack calculated from direct current of pSOFC; $P_{A C, N e t}$ denotes the overall system power, which is the summation of $\mathrm{AC}$ output of pSOFC AC, the low heat value of the methanol product, and the power consumption of compressor; 


\section{Results and discussion}

In this study, three systems with a same SOFC stack is used for simulation. The performance of SOFC in all the systems is proportional to the stack temperature as the conductivity of electrolyte increases with rise in temperature. The three proposed hybrid systems A, B, and $\mathrm{C}$ in this study are shown in Fig. 3. In system A, the $\mathrm{H}_{2} \mathrm{O}$ present in outlet gases of SOFC anode might decrease the methanol reactor efficiency with a reverse reaction as shown in the equation (15). So, a $\mathrm{H}_{2} \mathrm{O}$ separator is used between the SOFC and the input of methanol reactor in system $\mathrm{B}$. The $\mathrm{H}_{2} \mathrm{O}$ separator obstructs $\mathrm{H}_{2} \mathrm{O}$ entering the methanol reactor, thereby favors in higher methanol forming. The higher temperature of inlet gases in SOFC and methanol reformer favors the maintenance of higher temperature of systems. This might favor in higher efficiency of the system. So in system $\mathrm{C}$, a hydrogen transport membrane (HTM) is used at the inlet of SOFC. The outlet gases of reformer after separation from HTM are passed through cathode side of SOFC as a cooling media for maintenance of SOFC temperature. Also, the temperature of gas increases before it is fed into methanol reactor. The $\mathrm{H}_{2} \mathrm{O}$ in the high temperature gaseous passed through SOFC for heat exchange is separated by $\mathrm{H}_{2} \mathrm{O}$ separator before fed into methanol reactor. The effects of $\mathrm{H}_{2} \mathrm{O}$ separator, HTM and temperature of inlet gases on the performance of SOFC and methanol reactor will be explained further.

\subsection{SOFC stack efficiency}

In this study for SOFC operation, the stoichiometry of fuel ( Sto $\left._{\text {fuel }}\right)$ is varied from 1.4 to 1.7 with a constant stoichiometry of air $\left(\right.$ Sto $\left._{\text {air }}\right)$ as 3 . In general, Sto air $_{\text {of }} 3$ is usually preferred in the operation of SOFC stack. The stack efficiency of SOFC is seen in Fig. 4(a) is calculated using the equation (18). It can be clearly seen from Fig. 4(a) that the stack efficiency decreases with increase in Sto fuel. The unconsumed fuel with higher $\mathrm{Sto}_{\text {fuel }}$ decreases the efficiency of SOFC. From Fig. 4(a), it can be seen that, the stack efficiency of system $\mathrm{C}$ is little higher at 1.4 and $1.5 \mathrm{Sto}_{\text {fuel }}$ compared to system A and B. The fuel inlet for SOFC in system $\mathrm{C}$ is pure $\mathrm{H}_{2}$ as it passes through the HTM.

\subsection{Methanol reactor efficiency}

The excess gases from SOFC anode are fed to the methanol reactor. The unconsumed $\mathrm{H}_{2}$ from the $\mathrm{SOFC}$ is used for methanol production. So, the efficiency of methanol production increases with increase in the Sto fuel as seen in Fig. 4(b). But, the system B and C shows higher methanol production compared to system A. Whereas, system $\mathrm{C}$ shows higher production compared to system B. System B shows higher production compared to system A as the reverse mechanism mentioned in equation (15) is obstructed with presence of $\mathrm{H}_{2} \mathrm{O}$ separator as shown in Fig. 3. Whereas, in system $\mathrm{C}$, the temperature of the gases fed to methanol reactor is higher compared to system $\mathrm{B}$. Also, pure $\mathrm{H}_{2}$ gas is fed to the methanol reactor in system $\mathrm{C}$ compared to the hydrocarbon gas system A and B. So, the methanol production in higher in system $\mathrm{C}$ compared to system A and B.
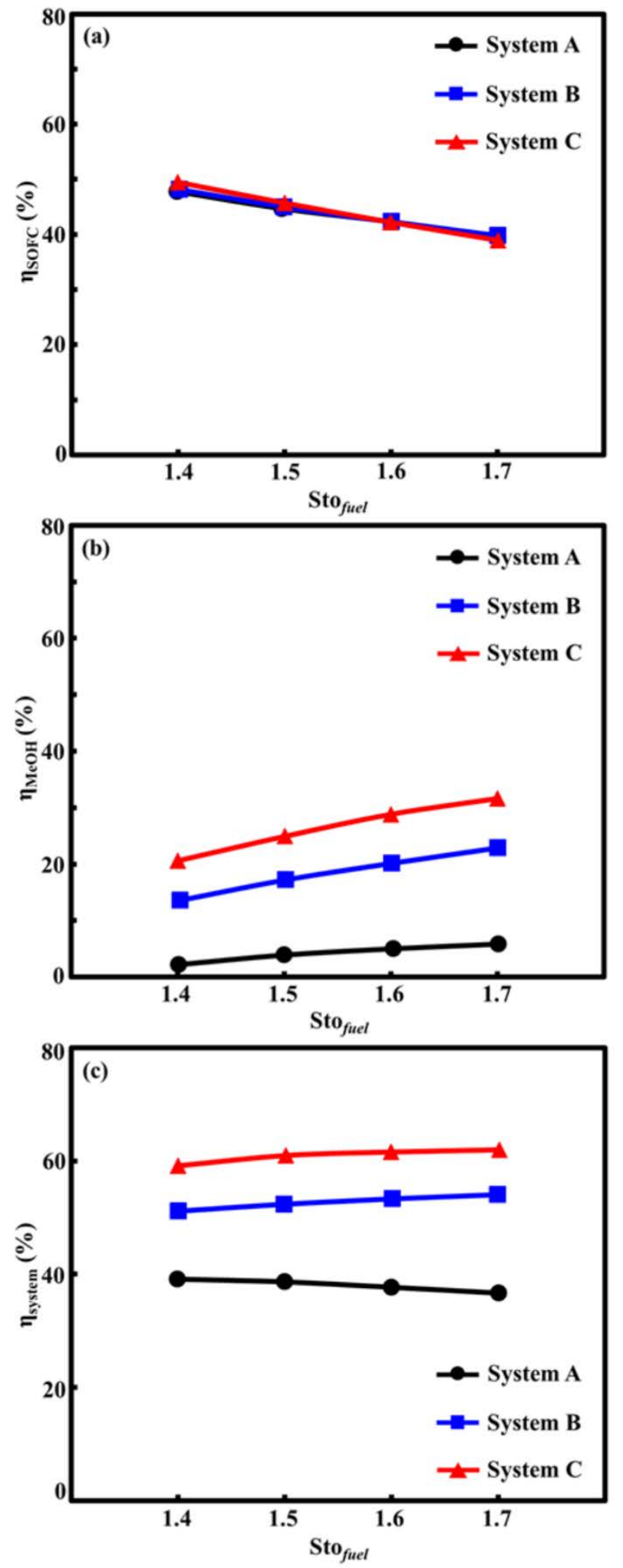

Fig. 4. Effects of $\mathrm{Sto}_{\text {fuel }}$ on (a) stack efficiency, (b) methanol reactor efficiency, and (c) system efficiency. 


\subsection{System efficiency}

The overall system efficiency comprises of pSOFC output power and the methanol production. The system efficiency of A, B, and C is shown in Fig. 4(c). In system A, the efficiency of system is approximately $36.5-39 \%$, which is lower than the stack efficiency (shown in Fig. 4 (a)), because of the lower methanol production. The methanol production efficiency for system $\mathrm{A}$ is approximately $6 \%$ (Fig. 4(b)). When the efficiency of methanol production cannot offset the energy losses of other components, the system efficiency declines (Fig. 4(c)). However, in system B, the system efficiency increases by $38 \%$ compared to system A with increase in the methanol production efficiency from $6 \%$ to $22 \%$. The system efficiency of system B increases with rise in the methanol production and Stofuel compared to system A. This system efficiency with rise in Sto fuel is in accordance with the equation (20). The system efficiency of system C is $14.8 \%$ higher compared to system B. Also seen in Fig. 4(b), the highest methanol production of $31 \%$ is observed for system $\mathrm{C}$ in comparison to system $\mathrm{A}$ and system $\mathrm{B}$. Thus, the large yield of methanol and net output of system compensates the losses and increases the efficiency of system C.

\subsection{Methanol reactor input gases}

\subsection{1 $\mathrm{H}_{2} \mathrm{O}$ mole fraction}

$\mathrm{H}_{2} \mathrm{O}$ separator is used in system $B$ and $D$ for obstructing the reverse reaction hindering the methanol production as mentioned in equation (15). Thus the increase in methanol production is observed in Fig. 4(b) and as explained in the previous section. The decrease in mole fraction of $\mathrm{H}_{2} \mathrm{O}$ with the presence of $\mathrm{H}_{2} \mathrm{O}$ separator at the input of methanol reaction can also be observed from Fig. 5(a).

\subsection{2 $\mathrm{H}_{2}$ mole fraction}

The production of $\mathrm{H}_{2}$ depends on the efficiency of steam methane reformer (SMR). The efficiency of SMR depends on the temperature of reforming. The temperature of the reformer also depends on the waste/recycled heat fed to the SMR in the system. The excess gases from the methanol reactor are fed to the burner for generation of heat. The heat generated in burner is fed to the SMR for temperature maintenance. The obstruction of water vapor into the methane reactor has increased the production of methanol and the temperature of outlet gases from methanol reactor. The higher temperature of methane reactor outlet gas with low amount of water vapor fed the burner increases the temperature of the outlet gas of burner. Thus the high temperature is maintained in burner. Further using the burner outlet gas for SMR temperature maintenance increases the efficiency of SMR in system B compared to system A. The excess fuel fed to SOFC stack is the input for methanol reformer. Thus, the $\mathrm{H}_{2}$ mole fraction for system B is higher compared to system A. Whereas in system $\mathrm{C}$, the passing outlet gases of SMR (except $\mathrm{H}_{2}$ ) favors the higher temperature maintenance of methanol reformer compared to system B. So, the efficiency of SMR in system C $>$ system B $>$ system A. Also, the higher mole fraction of unused $\mathrm{H}_{2}$ from SOFC stack is available for methanol reactor as seen in Fig. 5(b).
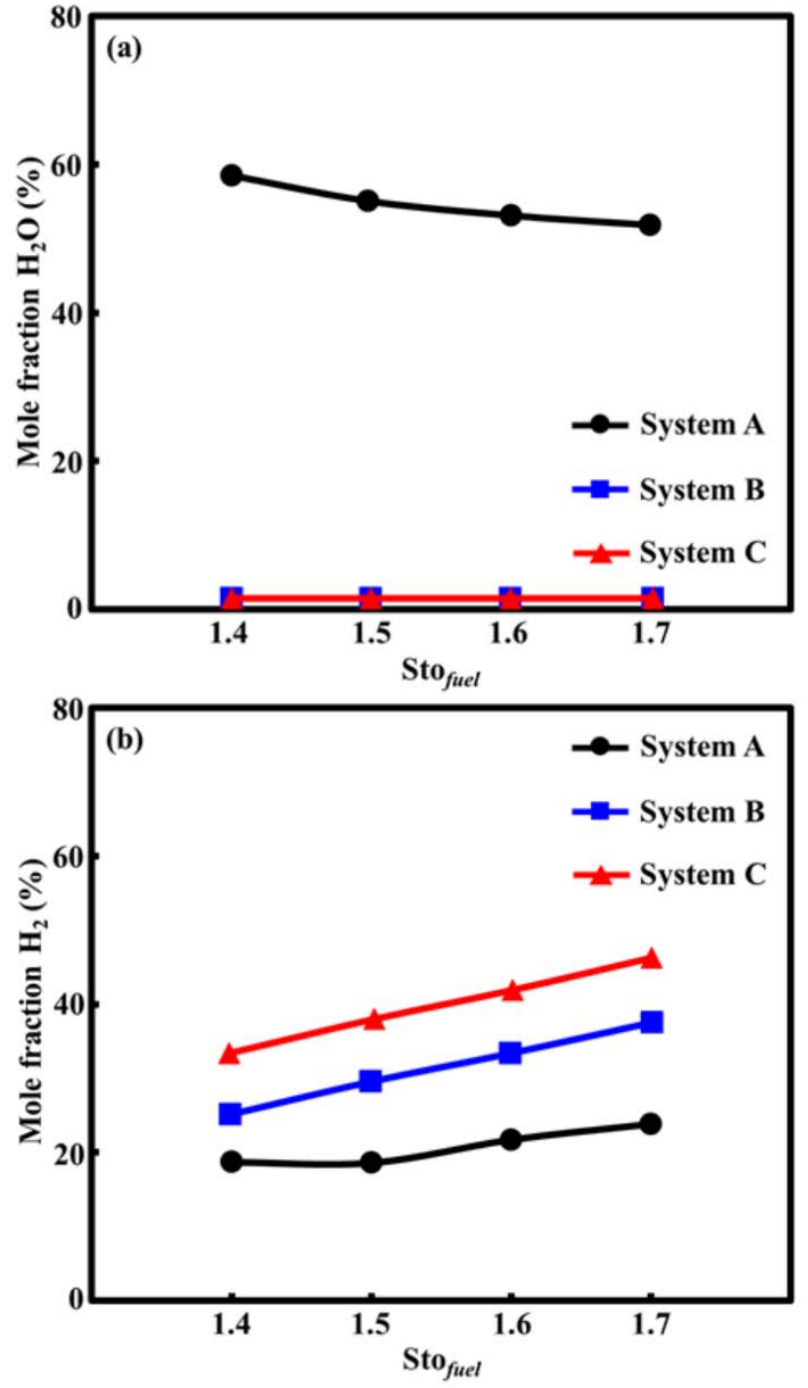

Fig. 5. Effects of Stofuel on methanol reactor inlet parameters (a) $\mathrm{H}_{2} \mathrm{O}$ mole fraction, and (b) $\mathrm{H}_{2}$ mole fraction.

\subsection{Carbon reduction}

In this study, the behavior of intermediatetemperature pSOFC hybrid systems is investigated. Low carbon emission is one of the advantages of a fuel cell. The extra $\mathrm{H}_{2}$ is recovered and combined with carbon to prepare methanol, which further reduces the carbon emission from integrated systems. In this study, the proportion of carbon reduction depends on the system parameters. The amounts of carbon reduction in system $\mathrm{A}, \mathrm{B}$ and $\mathrm{C}$ are $2.6 \%-7.3 \%, 17.1 \%-28.8 \%$, and $25.9 \%$ $39.6 \%$, respectively, as shown in Fig. 6 . The methanol production tends to increase when extra unconsumed fuel 
enters the methanol reactor. To find the reason of lower methanol production efficiency in system $\mathrm{A}$, the mole fraction of $\mathrm{H}_{2} \mathrm{O}$ is analyzed in the methanol reactor inlet. As seen in Fig. 5(b), the mole fraction of $\mathrm{H}_{2} \mathrm{O}$ is approximately $51 \%-60 \%$. According to equation (15), excessive $\mathrm{H}_{2} \mathrm{O}$ is unfavorable for the chemical reaction, and results in poor methanol production efficiency.

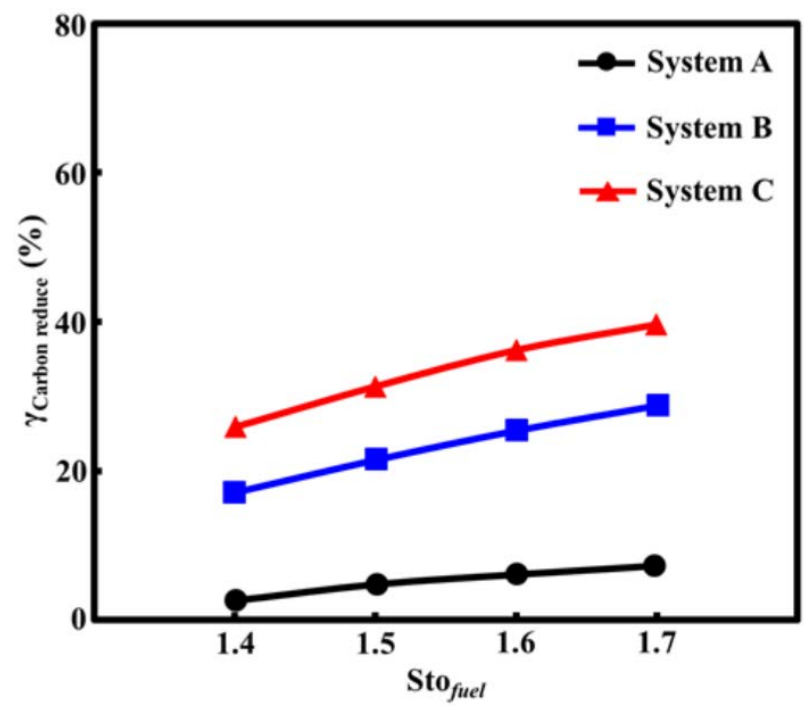

Fig. 6. Effects of $\mathrm{Sto}_{\text {fuel }}$ on carbon reduction property of systems.

Table 1. The comparison of carbon reduce proportion.

\begin{tabular}{|c|c|}
\hline Power plant & CO2 emission $(\mathbf{k g} / \mathbf{k W h})$ \\
\hline System A & 0.571 \\
\hline System B & 0.402 \\
\hline System C & 0.358 \\
\hline
\end{tabular}

However, the $\mathrm{H}_{2} \mathrm{O}$ separator is used to raise the methanol production efficiency in system $\mathrm{B}$. As shown in Fig. 5(a), the mole fraction of $\mathrm{H}_{2} \mathrm{O}$ is only approximately $1.5 \%$ in system $B$ and $C$; As a result of using $\mathrm{H}_{2} \mathrm{O}$ separator, the methanol production efficiency and carbon reduction is increased in system $\mathrm{B}$ and $\mathrm{C}$. The carbon reduction in system $\mathrm{C}$ is $25.9 \%-39.6 \%$, which is approximately $8.8 \%-10.8 \%$ higher than that of system B. Hence, system $\mathrm{C}$ performs excellent carbon reduction with higher methanol production (Table 2). System $C$ has the largest carbon reduction, and the highest economic benefits; therefore, system $\mathrm{C}$ is preferable compared to the other systems.

\section{Conclusions}

The behavior of IT-pSOFC hybrid system is studied in this work. The hybrid system comprises of a pSOFC stack, a methanol production reactor, and heat exchangers. Heat exchangers are used for waste heat recovery from the burner. The system performance is explored using Matlab/Simulink/Thermolib. Different Sto values are used to control the flow rates of air and hydrogen. Sto values for hydrogen in this study varies between 1.4-1.7. The benefit of carbon reduction is dependent on methanol production. Avoiding the presence of water vapor with $\mathrm{H}_{2}$ dramatically increases the methanol production efficiency. In addition, HTM, which was used to increase stack efficiency and control the temperature of stack chamber and reformer, further improves the benefit of carbon reduction.

\section{Acknowledgements}

This work is partially supported by the Ministry of Science and Technology of Taiwan.

\section{References}

1. M. Gandiglio, A. Lanzini, M. Santarelli, M. Arci, T. Hakala, M. Rautanen, Int. J. Hydrogen Energy 45, 5449 (2020).

2. D.J. Brett, A. Atkinson, N.P. Brandon, S.J. Skinner, Chem. Soc. Rev. 37, 1568 (2008).

3. A. Demin, P. Tsiakaras, Int. J. Hydrogen Energy 26, 1103 (2001).

4. A.K. Demin, P.E. Tsiakaras, V.A. Sobyanin, S.Y. Hramova, Solid State Ionics 152-153, 555 (2002).

5. M. Ni, M.K.H. Leung, D.Y.C. Leung, Fuel Cells 7, 269 (2007).

6. M. Ni, D.Y.C. Leung, M.K.H.Leung, J. Power Sources 183, 682 (2008).

7. Y. Patcharavorachot, N.P. Brandon, W. Paengjuntuek, S. Assabumrungrat, A. Arpornwichanop, Solid State Ionics 181, 1568 (2010). 45

8. A. Choudhury, H. Chandra, A. Arora, Renewable Sustainable Energy Rev. 20, 430 (2013).

9. H. Xu, Z. Dang, B.F. Bai, Appl. Therm. Eng. 50, 1101 (2013).

10. Y.F. Yi, A.D. Rao, J. Brouwer, G.S. Samuelsen, J. Power Sources 144, 67 (2005).

11. S. Wongchanapai, H. Iwai, M. Saito, H. Yoshida, J. Power Sources 223, 9 (2013).

12. R.J. Braun, S.A. Klein, D.T. Reindl, J. Power Sources 158, 1290 (2006).

13. N.S. Siefert, S. Litster, Appl. Energy 107, 315 (2013).

14. B. Tjaden, M. Gandiglio, A. Lanzini, M. Santarelli, M. Jarvinen, Energy Fuels 28, 4216 (2014).

15. A. Lanzini, T.G. Kreutz, E. Martelli, M. Santarelli, Int. J. Greenhouse Gas Control 26, 169 (2014).

16. W. Doherty, A. Reynolds, D. Kennedy, J. Power Sources 277, 292 (2015).

17. H. Iwahara, Solid State Ionics 28-30, 573 (1988).

18. A.R. Potter, R. T. Baker, Solid State Ionics 177, 1917 (2006). 